\title{
Annalisa Coliva on Wittgenstein and Epistemic Relativism
}

\author{
Martin Kusch
}

Received: 6 April 2012 /Accepted: 20 July 2012 /

Published online: 19 October 2012

(C) Springer Science+Business Media Dordrecht 2012

\section{Introduction}

Annalisa Coliva's Moore and Wittgenstein (2010a) offers a thorough, nuanced, sophisticated and original reading of the two philosophers' reflections on certainties and scepticism. In this paper I shall focus on the one line of argument in the book with which I disagree: the discussion of epistemic relativism. I shall focus my critique not only on the relevant section of the monograph (2010a: 188-203), but also on Coliva's paper "Was Wittgenstein an Epistemic Relativist?" (2010b). The paper is wider is scope than the section in that it draws together, and condenses, relevant and related considerations from all parts of the book.

\section{Interpreters}

Coliva starts with the remark that "[r]elativists and anti-relativists alike are nowadays mostly united in considering Wittgenstein an epistemic relativist" (2010a: 188; 2010b: 1). To prove her point she mentions eight texts between 1977 and 2006. To her line-up one could add Bloor (1996); Gier (1981); Gullvåg (1988); Grayling (2001); Haller (1995); Rhees (2003), and Vasiliou (2004), as well as authors who attribute to Wittgenstein closely related forms of conceptual relativism: Glock (1996, 2008) and Hacker (1996). More importantly, I am puzzled by the absence from Coliva's list of the equally numerous earlier contributions that, like her own, reject the case for calling Wittgenstein an epistemological relativist: Anscombe (1976); Bambrough (1991); Blackburn (2004); Crary (2007); Dilman (2004); Hertzberg (1976); Lear (1984); Morawetz (1978); O’Grady (2004); Putnam (1992); Rhees (2003); Schulte (1988); Sluga (1996); B. Williams (1971/1981, 1974-1975/1981); M. Williams (2007), and von Wright (1982). Some of Coliva's arguments overlap

M. Kusch $(\bowtie)$

Department of Philosophy, University of Vienna, Universitaetsstrasse 7, 1010 Vienna, Austria

e-mail: martin.kusch@univie.ac.at 
with lines of thought in this earlier literature. Considering it in detail, and building upon it, could have strengthened her case and given a more balanced picture of where the debate on the question of Wittgenstein's relativism has got to.

\section{Definitions}

Coliva characterises epistemic relativism as follows. First, "there could be ... different epistemic systems, none of which would be intrinsically correct". Second, each such system "would be, from a metaphysical point of view, as good as any other, and would certify (as true and) justified different propositions". Third, the choice between epistemic systems "couldn't be based on rational considerations", and thus "the passage from one epistemic system to another would always be a form of conversion or persuasion" (2010a: 188; 2010b: 1).

I do not disagree with this suggestion. But I propose going further and identifying various 'conditions of relativism', subsets or clusters of which are often regarded-by friends and foes alike - as necessary and sufficient. Several of these conditions are disjunctive and thus allow for further choices. I take these conditions from authors who have - in different contexts and debates-sought to reject or defend forms of epistemic or moral relativism.

(1) Dependence: A belief has an epistemic status (as epistemically justified or unjustified) only relative to an epistemic system or practice $(=S P)$. (Cf. Williams 2007: 94).

I write "epistemic system or practice" in order to indicate that Dependence is compatible with both a "generalist" and "particularist" understanding of epistemology. Dependence also allows for a further choice regarding $S P$ s. In saying that a belief has an epistemic status (as justified or unjustified) only relative to an $S P$, the relativist might refer to either the $S P$ of the relevant believer, or to the $S P$ of the attributor or evaluator. (Cf. White 2007; Williams 2007; Boghossian 2006: 72).

(2) Pluralism: There are, have been, or could be, more than one such epistemic system or practice.

Given Pluralism, relativism is compatible with the idea that our current $S P$ is without an existing alternative. Moreover, Pluralism permits the relativist to be highly selective in choosing those $S P \mathrm{~s}$ with respect to which relativism applies. He might for example restrict his relativistic thesis to just two $S P$ s. For instance, one can be a relativist about science and religion, considering each as an SP in the sense of Dependence.

(3) Exclusiveness: SPs are exclusive of one another. This can take two forms:

(a) Question-Centred Exclusiveness: There are sets of yes/no questions to which SPS give opposite answers.

(b) Practice-Centred Exclusiveness: There are no yes/no questions to which SPs give opposite answers since their concepts and concerns are too 
different. SPs exclude each other in that the consequences of one SP include such actions or behaviours as are incompatible with the actions and behaviours that are consequences of other SPs. Users or members of one $S P$ are not able to fully understand the actions and behaviours common in other SPs. (Cf. Williams 1974-75/1981, 1985).

Exclusiveness tries to capture the sense in which - under a relativistic conception of their relationship-SPs have to conflict. This idea is in tension with the further assumption, made by some authors, that relativism concerns incommensurable SPS (here such incommensurability involves differences in categories that rule out an identity of propositional content across these $S P \mathrm{~s}$ ). The option of Practice-Centred Exclusiveness covers this eventuality. Two $S P$ s can be compared, and can conflict, when they lead to, or require incompatible forms of action and behaviour in an at least roughly specifiable area of human affairs. The requirement that the area of human affairs be specifiable safeguards that there is a certain degree of comparability. And the demand that the forms of action and behaviour involved are incompatible, makes sure that the condition of conflict is met.

(4) Notional Confrontation: It is not possible for a group $G$, that holds an epistemic system or practice $S P_{1}$, to go over to an epistemic system or practice $\mathrm{SP}_{2}$ on the basis of a rational comparison between $\mathrm{SP}_{1}$ and $S P_{2}$. But $\mathrm{G}$ might be converted to $\mathrm{SP}_{2}$ without loosing its hold on reality. (Cf. Williams 1974-1975/ 1981, 1985)

A "notional" confrontation differs from a "real" confrontation; in the case of the latter a rationally motivated 'switching' is possible. A conversion is not an altogether irrational event. Being converted to a cause is not the same as being self-deceived, brainwashed or drugged. There is no assumption that a conversion is a phenomenon of psychological or social pathology. This idea is captured by the phrase "without losing its hold on reality" (Williams 1974-1975/1981: 139).

(5) Contingency: Which epistemic system or practice a group or individual finds itself holding is a question of historical contingency.

If the history of $G$ had been different- for instance, if $G$ had encountered certain other groups at certain points, or if $G$ had lacked the means to engage in certain types of costly investigations - $G$ 's current $S P$ would be substantially, perhaps even radically, different from what it is now. The contingency might reach deep: even those beliefs that one ordinarily deems 'self-evident' or 'completely certain' can be discovered to be contingent. Becoming aware of the contingency of one's views in this sense can, but need not, undermine the strength of one's conviction (Rosen 2001).

(6) Groundlessness: There can be no epistemic justification of one's own epistemic system or practice.

Groundlessness is rarely formulated as a distinct ingredient of epistemic relativism. But it is sometimes invoked in arguments meant to establish the truth of 
relativism. For instance, it is occasionally put forward that epistemic relativism results from the recognition that all $S P$ s are on a par insofar as none of them is able to justify itself without moving in an (illegitimate) circle (cf. Williams 2007: 95).

(7) Underdetermination: Epistemic systems and practices are not determined by facts of nature.

Underdetermination is not to be confused with the thesis that the world has no causal impact on SPS at all. The relativist is not-or need not-be committed to the view that $S P$ s are completely arbitrary. His point is rather that (many) more than one $S P$ is compatible with the given causal impact of the world.

(8) Symmetry: Epistemic systems and practices must not be ranked.

Symmetry can take a number of different forms that are worth distinguishing.

(a) Methodological Symmetry: All SPs are on a par vis-à-vis social-scientific investigations.

The best-known version of Methodological Symmetry is perhaps the "Symmetry" or "Equivalence Postulate" of the "Strong Programme" in the "Sociology of Scientific Knowledge": "... all beliefs are on a par with one another with respect to the causes of their credibility." (Barnes and Bloor 1982: 23). I generalise this "postulate" in order to detach it from the requirement that explanations must be causal.

(b) Non-Neutrality: There is no neutral way of evaluating different $\mathbf{S P}$.

Non-Neutrality is the main consideration usually invoked in defense of Symmetry.

(c) Equality: All SPs are equally correct.

Most characterisations of relativism - by friends and foes alike-take Equality to be the natural consequence of Non-Neutrality and thus the best way to spell out Symmetry. But Equality makes a stronger claim than Non-Neutrality. This becomes easy to appreciate once we remember the typical challenge to Equality: what is the point of view from which Equality is asserted? On the face of it, Equality appears to presuppose a neutral point of view from which we can somehow see that all $\boldsymbol{S P}$ s are equally correct. And this very claim jars with Non-Neutrality.

(d) Non-Appraisal: For a reflective person the question of appraisal of (at least some other) SPs does not arise. (Williams 1974-1975-1981, 1985).

Non-Appraisal seems to avoid the problems of Equality, while capturing the important core of Non-Neutrality. It is motivated by the thought of "intellectual distance": the idea that a reflective person holding one $S P$ might come to the conclusion that her own "vocabulary of appraisal" simply does not get a proper grip on the judgements and actions of another SP. It is not that this vocabulary could not possibly be applied at all - it is rather that such application seems forced, artificial and contrived. (Williams 1974-1975/1981: 141-2). 
(9) Tolerance: Epistemic systems or practices other than one's own, must be tolerated.

What do we gain from this nine-part characterization? We gain at least three things. First, we get a better appreciation for the idea that epistemic relativism is not one position but a spectrum of positions: the epistemic relativist faces a number of choices (e.g. as concerns different Symmetry principles). Second, since the characterization was constructed from the writings of various influential writers for and against relativism, we get a better grasp too of the variety of views that are currently ascribed to the relativist. And third, working with the nine-part characterization vis-à-vis Wittgenstein, makes the question of his epistemic relativism more tractable. Rather than asking whether Wittgenstein is a relativist, we can turn to querying whether we can find textual evidence for the more specific principles. And if we can find such evidence we can then turn to investigating how the different principles are related to one another.

\section{Was Wittgenstein an "Internal Rationalist"?}

Coliva's argument against attributing epistemic relativism to Wittgenstein has several distinct steps. The first step seeks to establish that Wittgenstein was not a Strawsonian "naturalist" but an "internal rationalist" (2010b: 6): that he thought that our acceptance of hinge propositions is not just "something animal" (1969: 359) but "fully rational" (2010b: 5). Obviously, our most basic beliefs - say, that the Earth has existed for a long time - cannot be justified by empirical evidence. Any attempt to do so would end up be circular. Wittgenstein himself seems sometimes tempted to conclude from this impossibility that our acceptance of hinge beliefs is not rational. Coliva demurs and accuses Wittgenstein of "working with too narrow a conception of rationality" (ibid.). On the appropriately wider conception, a belief can be "rationally mandatory", and its acceptance "intrinsically rational", even when we have no evidential warrants. Acceptance has these rational characteristics when

... what is so believed is a cornerstone of one or more of our language games, as it makes it possible for us to have those disciplines within which reasons for and against specific empirical propositions can be produced (ibid.).

The "cornerstone" metaphor can be made more precise by the observation that these beliefs are "at the limit of the system - as they are its conditions of possibility" (ibid.). Finally, Coliva believes that this train of thought works as an interpretation of Wittgenstein's own views despite his unduly narrow conception of rationality. This is so because Wittgenstein thinks of hinges as part of "logic" and thus as "part of the system in which reasons are produced and within which rationality has a home" (ibid.).

Coliva's reasoning is obviously indebted to Crispin Wright (2004). But I fail to understand how exactly the argument is supposed to run. We are to reject the idea that our hinge beliefs are just brute facts about us. And we are to accept that these hinges cannot be justified on the basis of empirical evidence within our language games. So 
far, so good. The problematic step is what follows next. Coliva urges that we are rationally committed to our hinges, despite the lack of evidence, since without them we would not have our current system of beliefs and language games. Without our hinges we would not be able to operate the distinction between rational and irrational beliefs, a distinction to which we are already committed.

I am not persuaded. It seems to me that all the argument achieves is to shift the naturalism from applying to our hinges to applying to our languages games. To see this we only need to ask whether our language games are justified? In reply, we cannot point to our hinges, on pain of circularity. But we cannot reject the question either - at least not if we wish to advocate internal rationalism rather than naturalism.

Finally, I doubt whether Wittgenstein's remarks, that hinges are part of logic, must be taken as an indication of internal rationalism. The relevant passages (1969: 342, $56,150)$ seem to me to be neutral between naturalistic and the internal-rationalist readings.

\section{Ptolemy and the Moon-Landing}

Consider the one-time hinge proposition according to which "nobody has ever been on the Moon". Wittgenstein repeatedly refers to this proposition as a certainty. Coliva ponders what it would have taken to change Wittgenstein's - or even Ptolemy's mind. Her answer is that "both Ptolemy and Wittgenstein would have been rationally persuaded to change their views had they had all the evidence available to us ..." And from this conviction Coliva moves swiftly to the conclusion that "there is just one system of justification - Science - which evolves and develops over time" (2010a: 190; 2010b: 7). Coliva is not worried by the existence of different paradigms:

... even where a change of "paradigm" occurs, ... it is the presence of new evidence, which is recalcitrant to being incorporated within a given theory, that calls for new explanation and hence for a new scientific model. (2010a: 190-1; 2010b: 7)

Coliva offers paragraphs 108 and 286 of On Certainty (1969) as proof that Wittgenstein shares her belief in the "one system of justification". 108 tells us that we "should feel ourselves very distant from someone" who denied our evidence that (by 1951) no-one had been to the moon. 286 wonders what we would say (again in 1951) about a tribe who claims that moon travel is possible: "If we compare our system of knowledge with theirs then theirs is evidently the poorer one by far."

Paragraphs 108 and 286 have been used as evidence against relativistic readings of On Certainty before (Morawetz 1978; Williams 2007). But advocates of such readings have offered replies (Rhees 2003: 74; Kusch 2010: 229). To quote my own earlier commentary on the final sentence of 286 :

I do not accept that this passage is an expression of anti-relativism. Wittgenstein here describes what 'we' would think and say upon encountering these tribesmen. And he is undoubtedly correct: this is indeed what we (or most of us) would think and say. But to point out this obvious truth is not to reject or refute 
relativism; it is merely to characterize our prima facie, or naïve response to an encounter with a radically different epistemic system. The relativist does not deny that we are prone to respond in this way - after all it is his goal to convince us that this spontaneous reaction is not rationally licensed in the way some philosophers take it to be.

Paragraph 108 can be glossed in similar ways: of course we "should feel ourselves very distant from someone" who did not accept our evidence for the moon-landing. But far from being a consideration against relativism, this is exactly what should be expected on relativistic premises.

Turning from the interpretation of Wittgenstein to the intrinsic merit of Coliva's reasoning, I again have to confess my disbelief. Consider the counterfactual claim 'if Ptolemy had been presented with our evidence he would have accepted the possibility of landing on the moon'. Relying on familiar ways of analysing counterfactuals this amounts to the same as saying that, in the closest possible world in which Ptolemy is presented with our evidence, he accepts the possibility of a moon-landing. This claim is false. In the closest possible world Ptolemy has not yet been systematically reeducated to think and evaluate evidence as we do; he has not yet learnt all about modern physics and astronomy; and he has not yet acquired the basics of modern mathematics. And thus in the closest possible world he dismisses our evidence as incomprehensible and absurd - after all, our evidence, our criteria of justification and our natural-scientific knowledge are closely intertwined.

Perhaps there is also a hidden circularity in Coliva's train of thought. She assumes that Ptolemy will accept our evidence. And that he does accept our evidence, is proof that there is only "one system of justification". But what justifies the initial assumption that Ptolemy will accept our evidence? Is it not the idea that there cannot be alternative systems of justification?

\section{Science and Magic}

Having convinced herself that Ptolemy, Wittgenstein and our scientists are all (potential) participants in the one system of justification called "Science", Coliva goes on to investigate the relationship between science and magic. This is as it should be; after all, Wittgenstein has often been assumed to hold a relativist view of this relationship. For instance, he sometimes indicates that only "persuasion" or "conversion" could move us from the one to the other (1969: 92, 262, 612).

Coliva has no time for such views. Some tribes study the intestines of chickens to predict the weather. Is this an epistemic system alternative to ours? Does this offer a counterexample to the "one system" claim? No. The degree of decomposition of the animals' interiors "could be an indicator of the humidity present in the air". And then "divination, once deprived of all its symbolic and religious elements, would be just a piece of, as it were, 'primitive' Science". Coliva finds support for this rendering in Wittgenstein where he writes (in his "Remarks on Frazer") that "primitive" tribesmen's "knowledge of nature would not differ fundamentally from ours" (Coliva 2010a: 192; 2010b: 8; Wittgenstein 1993: 141). But is it appropriate and permissible to leave out "all ... symbolic and religious elements"? According to Coliva this 
depends on the exercise we are engaged in. As long as we are doing epistemology, we are permitted to "judge [the tribesmen's] epistemic practices, taken as such, and deem them erroneous (...), or at any rate, 'primitive' ..." (2010a: 193; 2010b: 9).

In this context Coliva also comments on Peter Winch's contention that our epistemic system is different from the Azandes' in that we pay attention only to efficient causes, and the Azande only to final causes (1964: 38). Coliva disagrees. She reminds us that, according to Edward Evans-Pritchard's famous study (1937) of the Azande, the latter understand, and operate with, both efficient and final causes:

This opens up the possibility of saying that our scientific attitude is more advanced insofar as our account of efficient causes is better than theirs; while also maintaining that their magical practices aren't a sufficiently strong ground to motivate the idea that they embrace a different epistemic system. (2010a: 193; 2010b: 10)

Coliva thinks that Wittgenstein agrees with her-again in the "Remarks on Frazer" (1993: 129). Her Wittgenstein distinguishes between opinions and theories about nature on the one hand, and "symbolic and religious elements" on the other hand. The "primitives" do not achieve a clear separation of the two aspects; we do. (2010a: 195; 2010b: 10).

I read Wittgenstein's "Remarks on Frazer" very differently. These notes aim to deconstruct Frazer's opposition between us and the "savages". According to Frazer we have true physics, the "savages" have magic or false physics. The "savages" are trapped in magical practices; we however are free. Wittgenstein insists on symmetry: the "savages" have many true beliefs about nature, and we too are steeped in rituals and ceremonies.

Wittgenstein writes that the "same savage, who stabs the picture of his enemy apparently in order to kill him, really builds his hut out of wood and carves his arrow skilfully and not in effigy" (1993: 125). Contrary to what Frazer alleges, the "savages" do not have "a completely false (even insane) idea of the course of nature ... Only their magic is different." (1993: 141). And Wittgenstein puts the main difference between science and magic as follows: "in science there is progress, but in magic there isn't" (ibid.)

And we have magic too. Many of us have a religion; many of us confess our sins to a priest; we sometimes burn letters when relationships break up; we kiss the picture of a beloved; we hit trees to vent our anger; and we squeeze our lips together to make someone else be quiet. These kinds of actions are not leftovers from a magical past; they are part and parcel of being human. Frazer fails to recognize that "man is a ceremonial animal" and that ...

... one could begin a book on anthropology by saying: When one examines the life and behaviour of mankind through the world, one see that, except for what might be called animal activities, such as ingestion, etc. etc., men also perform actions which bear a characteristic peculiar to themselves, and these could be called ritualistic actions. (1993: 129)

I agree with Coliva that Wittgenstein emphasises commonalities between "us" and the tribesmen, and on both sides of the science-magic divide. But these commonalities 
are not the key issue here. What is in dispute is how magic and science relate to one another. Remember Coliva's Wittgenstein's central move. He splits magic up in two parts: (a) the symbolic/religious part, and (b) the epistemic/(proto-)scientific part. (b) is of a piece with our science. The history of our (Western) science has shown that (a) can be separated from (b); this constitutes progress and demonstrates the superiority of science over magic.

None of these claims are correct on my reading of the textual evidence. Wittgenstein does not distinguish between two sides-proto-science and religionwithin magic, but between magic and science. He does not set science above magic on the grounds that the former has cut itself loose from its magical past. Nor does he propose any other epistemic grounds on the basis of which science is epistemically superior to magic. Indeed, there is no suggestion that Wittgenstein would accept Coliva's ways of contrasting epistemic practices with religious or magical practices in the first place.

\section{Logic}

Coliva endeavours to show that Wittgenstein is with her in rejecting the idea that another culture could have a logic different from ours. Winch (1964) offers the Azande as an example of a culture that rejects modus ponens: the Azande both believe that witchcraft transmits patrilineally, and that the son of a male witch need not be a witch himself. Coliva offers a different interpretation of the Azandes' reasoning: it is not that they reject modus ponens, they merely choose to restrict its domain of application. Coliva finds a similar phenomenon in Catholics' belief in the trinity:

Now, I think we would resist the idea that Catholics have a different logic than ours and that we would rather say that certain issues remain insulated from the employment of logic." (2010a: 196; 2010b: 12)

Coliva takes Wittgenstein to express a similar view when he writes that Catholic "dogma ... is unshakable, but at the same time any practical opinion can be made to harmonize with it ..." (ibid.; Wittgenstein 1980: 28)

Coliva goes on to challenge Paul Boghossian's rendering of Wittgenstein's views on logic. Boghossian puts Wittgenstein on Winch's side, before going on to criticize logical relativism:

If the Azande employ different rules for inferences involving 'if,' (or the Azande equivalent) this would simply show that they mean something different by that word than we do by 'if." (2006: 107)

Boghossian presses the point also with respect to Wittgenstein's famous "odd wood-sellers" who sell wood by area covered and without paying attention to how high the wood is piled up. Boghossian dismisses the thought that the odd woodsellers mean by "wood", "cost" or "more" what we do but that they employ a different 
logic: "Surely, it is far more plausible that these people mean something different by 'more' or 'cost' than we do ..." (2006: 109).

Coliva agrees with Boghossian's criticism of logical relativism but seeks to exonerate Wittgenstein from the charge of endorsing this view. As Coliva sees it, Wittgenstein considers two options concerning our encounter with the odd woodsellers: either we are able to convince them that their practice is irrational, or we must come to realize that our translation of their words was mistaken:

Hence, Wittgenstein turns out to be in complete agreement with Boghossian in thinking that just by conceiving of a possibly different community, which is recalcitrant to rational persuasion, we wouldn't have discovered ipso facto a different epistemic system alternative to ours. (2010a: 197; 2010b: 14).

I fully agree with this sentence. Nevertheless, it seems to me important to consider not only Wittgenstein's discussion of the odd wood-sellers in the Remarks on the Foundations of Mathematics (where the relevant passage is from 1937) but also in the Lectures on the Foundations of Mathematics (from 1939). In the later treatment the first step is the suggestion that the tribesmen's word for their wood-distribution practice is best translated as "giving wood away". This alternative is introduced as an attempt to protect the tribesmen from the accusation of logical madness: "We might call this a kind of logical madness. But there is nothing wrong with giving wood away." (1939/1976: 202.) The second step is charitable in a different sense: now the tribesmen get off the hook by being no worse than us: "What the hell's the point of doing this? ... It isn't clear in all that we do, what the point is." (1939/1976: 203-4.) And in a third step Wittgenstein proposes a "historical explanation" of the tribe's practice:

(a) These people don't live by selling wood ... (b) A great king long ago told them to reckon the price of wood by measuring just two dimensions, keeping the height the same. (c) They have done so ever since, except that they later came not to worry about the height of the heaps. Then what is wrong? They do this. And they get along all right. What more do you want? (1939/1976: 204)

This third step is especially noteworthy. It shows that Wittgenstein allows for the possibility that the tribesmen might have a practice of selling wood that - although it seems irrational by our standards - is perfectly sensible for the tribesmen.

Perhaps we might say that, in the quoted passage, Wittgenstein submits that the tribesmen suspend logic when it comes to selling wood. This would bring the passage in line with Coliva's first point, according to which the Azande and the Catholics are best thought of, not as rejecting modus ponens, but as restricting its domain of application.

I beg to differ. Imagine we came across a culture that has modified the game of chess in the following way: when moving on their respective halves of the board, the two players follow the familiar rules of chess. But when moving their pieces on their opponents' half, the players move their pieces according to different rules (e.g. queens then move like rooks, rooks like knights, etc.). Suppose someone said that this culture plays chess according to different rules. Would we really think it an appropriate 
response to say: No, they do not play according to different rules, they simply restrict the domain of the familiar rules? I think not. Put differently, there is nothing in the Azandes' dealing with witchcraft and its heredity transmission that forces us to speak of their using our logic, or the one logic, in a restricted domain. The situation could also be described as their using a different logic. After all, the domain-specificity of the logical rules might be part of the rules very content.

\section{Alternative World-Pictures}

Coliva's considerations up to this point all concern the question whether Wittgenstein was a "factual epistemic relativist". The last third of her paper addresses the further issue whether Wittgenstein was a "virtual epistemic relativist". A virtual epistemic relativist believes that it is possible to have "at least in principle, different, yet perfectly legitimate and intelligible, world-pictures" (2010a: 197; 2010b: 15-16). Coliva is adamant that Wittgenstein rejects the virtual version: her reason for this verdict is Wittgenstein's above-mentioned alleged rejection of alternative logics. But why then does Wittgenstein so often ask us "to imagine allegedly radically different communities"? (2010a: 201; 2010b: 20). Coliva's answer is this:

The value of what in the end appears to be an entirely notional exercise is, I believe, to make us aware of the ungroundedness of our own world-picturethat is to say, of its contingency. (2010a: 202; 2010b: 21)

Here too Coliva's argument could have benefited from investigating previous rounds of debate. After all, this very issue has been the focus on the controversy over Wittgenstein's alleged "idealism" (cf. Williams 1971; Anscombe 1976; Malcolm 1981; Bolton 1981; Lear 1984; Stroud 1984; Bloor 1996; Blackburn 2004).

Bernard Williams argues that Wittgenstein is not "concerned so much with the epistemology of differing world-views ... as with ways of exploring our own worldview" (1971/1981: 159). What interests Wittgenstein, Williams maintains, is our and only our language and world. And to explore these, Wittgenstein finds it important to imagine alternatives, to test how far we can stretch our language and "still remain without our world - a world leaving which would not mean that we see something different, but just that we ceased to see." (1971/1981: 160) Thus when Wittgenstein speaks about our meeting a king who believes he has been to the moon, or a tribe that relies on oracles rather than science, he is not concerned with the question whether the epistemic system of the king or the tribe is as valid as is our physics. He is rather trying to find out whether our talk of such a scenario is meaningful or not, whether it describes a situation that makes sense.

Williams' ideas have been developed further by Jonathan Lear (1984). Lear focuses on "the disappearing we". Initially it seems as if "our we" is different from, and opposed to, other "we's" insofar as our language-games are different from, and opposed to, their language-games. But the plurality collapses once we realize that the (transcendental) language is but one single language: "we come to see that being one of 'our' representations is all that there could be to being a representation. ... The concept of being minded in any way at all is 
that of being minded as we are." (1984; 233) Like Williams, so also Lear concludes that Wittgenstein's idealism precludes a genuine interest in the differences between cultures - and thus in relativism:

Thought may have to be understood in the context of customs, practices and institutions, but Wittgenstein seems indifferent to the study of any particular community. His thought seems to stand to sociology as Kant's was intended to stand to empirical psychology." (1984: 240)

This is not the place to argue with Williams and Lear. I therefore confine myself to a brief comment on Coliva's suggestion according to which the point of the "notional exercise" of imagining "radically different communities" is to make us aware of the "contingency" of our world-picture. (2010a: 202; 2010b: 20-21). This is not how Williams and Lear see it, and I am with them: the realization that we cannot imagine radically different practices, cannot justify the thought that our practices are contingent.

\section{Conclusion}

In this paper I have outlined my quibbles concerning Coliva's answering of the question "Was Wittgenstein an Epistemic Relativist?". I have proposed considering a larger corpus of previous contributions to the issue; I have offered a broader (and in part disjunctive) characterization of epistemic relativism; and I have expressed doubts about four key arguments: that Ptolemy would accept our scientific evidence for the moon-landing; that Wittgenstein thinks of magic as a form of proto-science; that we can make no sense of an alternative logic; and that Wittgenstein introduces imaginary radically different communities in order to remind us of the contingency of our own practices.

\section{References}

Anscombe, G. E. M. (1976). The question of linguistic idealism. Acta Philosophica Fennica, 27, $188-215$. Bambrough, R. (1991). Fools and heretics. In A. Phillips Griffiths (Ed.), Wittgenstein: Centenary essays (pp. 239-250). Cambridge: Cambridge University Press.

Barnes, B., \& Bloor, D. (1982). Relativism, rationalism and the sociology of knowledge. In M. Hollis \& S. Lukes (Eds.), Rationality and relativism (pp. 21-47). Oxford: Blackwell.

Blackburn, S. (2004). Relativism and the abolition of the other. International Journal of Philosophical Studies, 12, 245-258.

Bloor, D. (1996). The question of linguistic idealism revisited. In H. Sluga \& D. G. Stern (Eds.), The Cambridge Companion to Wittgenstein (pp. 354-82). Cambridge, England: Cambridge University Press.

Boghossian, P. (2006). Fear of knowledge: Against relativism and constructivism. Oxford: Clarendon.

Bolton, D. (1981). Life-form and Idealism, in Vesey (1981), 269-284.

Coliva, A. (2010a). Moore and Wittgenstein: Scepticism, certainty, and common sense. Houndsmill, Basingstoke: Palgrave, MacMillan.

Coliva, A. (2010b). Was Wittgenstein an epistemic relativist? Philosophical Investigations, 33, 1-23.

Crary, A. (2007). Wittgenstein and ethics: A discussion with reference to On Certainty. In D. MoralSharrock \& W. H. Brenner (Eds.), Readings of Wittgenstein's On Certainty (pp. 275-301). Houndmills, Basingstoke: Palgrave McMillan. 
Dilman, I. (2004). Wittgenstein and the question of linguistic idealism. In D. McManus (Ed.), Wittgenstein and scepticism (pp. 162-177). London: Routledge.

Evans-Pritchard, E. E. (1937). Witchcraft, oracles and magic among the azande. Oxford University Press.

Gier, N. F. (1981). Wittgenstein and phenomenology: A comparative study of the later Wittgenstein, Husserl, Heidegger, and Merleau-Ponty. Albany, N.Y.: State University of New York Press.

Glock, H.-J. (1996). A Wittgenstein dictionary. Oxford: Blackwell.

Glock, H.-J. (2008). Relativism, commensurability and translatability. In J. Preston (Ed.), Wittgenstein and reason (pp. 21-46). Oxford: Blackwell.

Grayling, A. (2001). Wittgenstein on scepticism and certainty. In H.-J. Glock (Ed.), Wittgenstein: A critical reader (pp. 305-321). Oxford: Blackwell.

Gullvåg, I. (1988). Remarks on Wittgenstein's Über Gewissheit and a Norwegian Discussion. Inquiry, 31, 371-385.

Hacker, P. M. S. (1996). On Davidson's idea of a conceptual scheme. The Philosophical Quarterly, 46, 289-307.

Haller, R. (1995). Was Wittgenstein a Relativist? In R. Egidi (Ed.), Wittgenstein: Mind and language (pp. 223-231). Dordrecht: Kluwer.

Hertzberg, L. (1976). On the factual dependence of the language-game. Acta Philosophica Fennica, 28, $126-148$.

Kusch, M. (2010). Kripke's Wittgenstein, On Certainty, and epistemic relativism. In D. Whiting (Ed.), The later Wittgenstein on language (pp. 213-237). Houndmills, Basingstoke: Palgrave Macmillan.

Lear, J. (1984). The Disappearing 'We'. Proceedings of the Aristotelian Society, Suppl. Vol. 58, $219-242$.

Malcolm, N. (1981). "Wittgenstein and idealism", in Vesey (1981), 132-43.

Morawetz, T. (1978). Wittgenstein and knowledge: The importance of On Certainty. Amherst: The University of Massachusetts Press.

O’Grady, P. (2004). Wittgenstein and relativism. International Journal of Philosophical Studies, 12, 315337.

Putnam, H. (1992). Renewing philosophy. Cambridge, Mass.: Harvard University Press.

Rhees, R. (2003). In D. Z. Phillips (Ed.), Wittgenstein's On Certainty: There - like our life. Oxford: Blackwell.

Rosen, G. (2001). Nominalism, naturalism, epistemic relativism. Philosophical Perspectives, 15, 60-91.

Schulte, J. (1988). World-picture and mythology. Inquiry, 31, 323-334.

Sluga, H. (1996). Ludwig Wittgenstein: Life and work. In H. Sluga \& D. G. Stern (Eds.), The Cambridge Companion to Wittgenstein (pp. 1-33). Cambridge, England: Cambridge University Press.

Stroud, B. (1984). The allure of idealism. Proceedings of the Aristotelian Society, 58, 219-242.

Vasiliou, I. (2004). Wittgenstein, religious belief, and On Certainty. In R. L. Arrington \& M. Addis (Eds.), Wittgenstein and philosophy of religion (pp. 29-50). London: Routledge.

von Wright, G. H. (1982). Wittgenstein. Oxford: Basil Blackwell.

White, R. (2007). Epistemic subjectivism. Episteme, 4, 115-129.

Williams, B. (1971/1981). Wittgenstein and Idealism, in Williams (1981), 144-163. (First published in 1971.)

Williams, B. (1974-1975/1981). The truth in Relativism, in Williams (1981), 132-143. (First published in 1974-1975.)

Williams, B. (1981). Moral luck (pp. 132-143). Cambridge: Cambridge University Press.

Williams, B. (1985). Ethics and the limits of philosophy. London: Fontana.

Williams, M. (2007). Why (Wittgensteinian) contextualism is not relativism. Episteme, 4, 93-114.

Winch, P. (1964). Understanding a Primitive Society, reprinted in Winch, 1972, Ethics and Action, London: Routledge, 8-49.

Wittgenstein, L. (1969). On Certainty. Oxford: Blackwell.

Wittgenstein, L. (1976). In C. Diamond (Ed.), Wittgenstein's Lectures on the Foundations of Mathematics, Cambridge 1939. Chicago, Il: Chicago University Press.

Wittgenstein, L. (1980). Culture and value. Chicago: University of Chicago Press.

Wittgenstein, L. (1993). Remarks on Frazer's Golden Bough, in Wittgenstein. (1993). Philosophical occasions: 1912-1951, ed. J.C. Klagge and A. Nordman, Indianapolis: Hackett, 118-155.

Wright, C. (2004). Wittgensteinian Certainties. In D. McManus (Ed.), Wittgenstein and scepticism (pp. 2255). London: Routledge. 